University of Nebraska - Lincoln

DigitalCommons@University of Nebraska - Lincoln

Roger Kirby Publications

Research Papers in Physics and Astronomy

May 1994

\title{
Magnetic and magneto-optic properties of sputtered Co/Ni multilayers
}

\author{
Y. B. Zhang \\ University of Nebraska - Lincoln \\ P. $\mathrm{He}$ \\ University of Nebraska - Lincoln \\ John A. Woollam \\ University of Nebraska-Lincoln, jwoollam1@unl.edu \\ J. X. Shen \\ University of Nebraska - Lincoln \\ Roger D. Kirby \\ University of Nebraska-Lincoln, rkirby1@unl.edu \\ See next page for additional authors
}

Follow this and additional works at: https://digitalcommons.unl.edu/physics_kirby

Part of the Physics Commons

Zhang, Y. B.; He, P.; Woollam, John A.; Shen, J. X.; Kirby, Roger D.; and Sellmyer, David J., "Magnetic and magneto-optic properties of sputtered Co/Ni multilayers" (1994). Roger Kirby Publications. 17.

https://digitalcommons.unl.edu/physics_kirby/17

This Article is brought to you for free and open access by the Research Papers in Physics and Astronomy at DigitalCommons@University of Nebraska - Lincoln. It has been accepted for inclusion in Roger Kirby Publications by an authorized administrator of DigitalCommons@University of Nebraska - Lincoln. 


\section{Authors}

Y. B. Zhang, P. He, John A. Woollam, J. X. Shen, Roger D. Kirby, and David J. Sellmyer 


\title{
Magnetic and magneto-optic properties of sputtered $\mathrm{Co} / \mathrm{Ni}$ multilayers
}

\author{
Y. B. Zhang, P. He, and J. A. Woollam \\ Center for Microelectronic and Optic Materials Research, and Department of Electrical Engineering, \\ University of Nebraska, Lincoln, Nebraska 68588 \\ J. X. Shen, R. D. Kirby, and D. J. Sellmyer \\ Center for Materials Research and Analysis, and Department of Physics, University of Nebraska, \\ Lincoln, Nebraska 65588
}

\begin{abstract}
We have investigated the magnetic and magneto-optic properties of $\mathrm{Co} / \mathrm{Ni}$ multilayers deposited on $\mathrm{Ag}$ and $\mathrm{Au}$ buffer layers. The samples with $\mathrm{Au}$ buffer layers show perpendicular magnetic anisotropy, but those with $\mathrm{Ag}$ buffer layers do not. The structure and degree of crystalline alignment of the buffer layer are evidently crucial to development of perpendicular magnetic anisotropy. We also present the results of polar Kerr rotation measurements as a function of wavelength and layer thickness of the multilayers.
\end{abstract}

\section{INTRODUCTION}

Magnetic multilayers have attracted much attention ${ }^{1}$ due to the resulting novel properties that are suitable for a variety of applications. One interesting phenomenon is the so-called perpendicular magnetic anisotropy that has been found in $\mathrm{Co} / \mathrm{X}$ (X being a nonmagnetic metal such as $\mathrm{Pt}, \mathrm{Pd}, \mathrm{Au}$, or $\mathrm{Ir}$ ) multilayers. ${ }^{2-4}$ The large perpendicular magnetic anisotropy shown in these multilayers makes them potential candidates for MO recording media. Recently, $\mathrm{Co} / \mathrm{Ni}$ multilayers were also predicted to have perpendicular magnetic anisotropy, and this was confirmed in $e$-beam evaporated multilayer samples. ${ }^{5}$ Magneto-optic and thermomagnetic writing tests on this e-beam evaporated multilayer have yielded encouraging results. ${ }^{\circ}$

In this article, the magnetic and magneto-optic properties of sputtered $\mathrm{Co} / \mathrm{Ni}$ multilayers are reported. The effects of $\mathrm{Au}$ and $\mathrm{Ag}$ buffer layers on the perpendicular magnetic anisotropy of the sputtered $\mathrm{Co} / \mathrm{Ni}$ multilayers are discussed, then the dependencies of the magneto-optic properties on the wavelength and the multilayer structure parameters are presented.

\section{EXPERIMENT}

Samples were prepared using both $\mathrm{dc}$ and if magnetron sputtering. The system was first evacuated to below $5 \times 10^{-7}$ Torr before sputtering, and $\mathrm{Ar}$ gas $\left(5 \times 10^{-3}\right.$ Torr) was used in the sputtering process. In most cases, 50-nm-thick Au or Ag buffer layers were first deposited onto glass substrates. The Co thickness was varied from 0.1 to $0.4 \mathrm{~nm}$ and the $\mathrm{Ni}$ thickness from 0.2 to $1.2 \mathrm{~nm}$. Multilayered structures were realized by rotating the substrates above the separate guns. The total Co/Ni thickness was varied between 5 to $30 \mathrm{~nm}$.

The magnetic properties were measured using an alternating gradient force magnetometer (AGFM). Crystalline texture studies were performed using $\mathrm{x}$-ray diffractometry with a $\mathrm{Cu} K \alpha$ target in the $\theta-2 \theta$ mode, and a scanning angle of $10^{\circ}-90^{\circ}$. The Kerr rotation $\left(\theta_{k}\right)$ and the Kerr ellipticity $\left(\epsilon_{k}\right)$ were measured at normal incidence over the wavelength range from 300 to $800 \mathrm{~nm}$ ușing apparatus previously described. $^{7}$ All experiments are performed at room temperature.

\section{RESULTS AND DISCUSSIONS}

Figure 1(a) shows hysteresis loops obtained with the AGFM for $\mathrm{Co}(0.2 \mathrm{~nm}) / \mathrm{Ni}(0.8 \mathrm{~nm})$ on $\mathrm{Ag}$ for magnetic fields applied both in the plane and perpendicular to the film plane. Clearly, this sample has in-plane magnetic anisotropy, as did all other samples deposited on $\mathrm{Ag}$ buffer layers. In contrast, Fig. 1(b) shows perpendicular and parallel hysteresis loops for a similar multilayer deposited on a Au buffer layer. This sample clearly has perpendicular anisotropy, and the value of the uniaxial anisotropy constant (as determined by the looparea method) is about $100 \mathrm{~kJ} / \mathrm{m}^{3}$. All of our $\mathrm{Co} / \mathrm{Ni}$ multilayers deposited on Au showed perpendicular anisotropy, in agreement with the results of Daalderop et al..$^{5}$

While the origins of perpendicular magnetic anisotropy (PMA) are often difficult to determine, PMA can be due to tensile internal stresses. ${ }^{8}$ Thus the structural details of the buffer layer may be of considerable importance in determining the magnitude of the anisotropy. Figure 2 shows $\mathrm{x}$-ray diffraction scans of the fcc $\mathrm{Au}$ and $\mathrm{Ag}$ buffer layers, each 50 $\mathrm{nm}$ thick. The dominant feature of hoth scans is the [111]
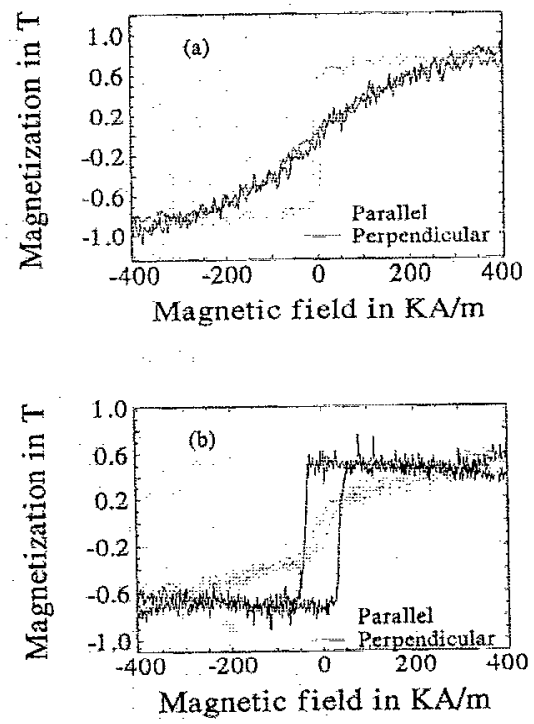

FIG. 1. Room temperature hysteresis loops for (a) $\mathrm{Co}(0.2) / \mathrm{Ni}(0.8) \times 12 \mathrm{mul}-$ tilayers on $\mathrm{Ag}$ buffer layers and (b) $\mathrm{Co}(0.2) / \mathrm{Ni}(0.8) \times 8$ on Au buffer layers. 


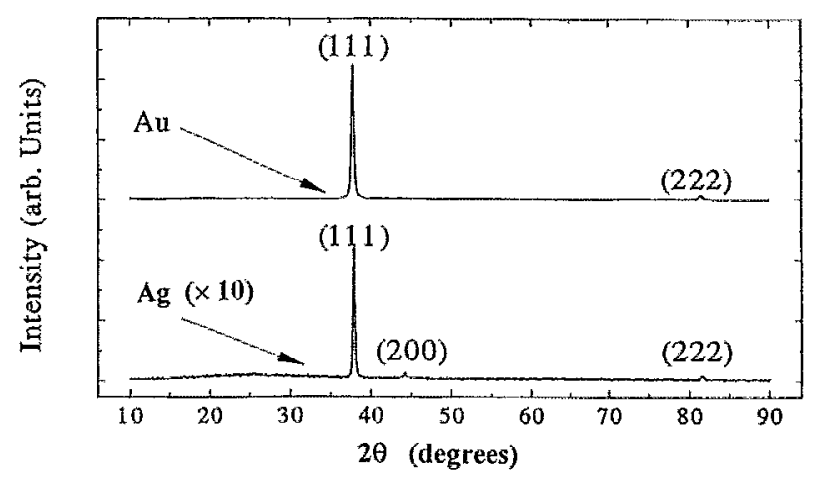

FIG. 2. $2 \theta \mathrm{x}$-ray diffraction patterns of $\mathrm{Au}$ and $\mathrm{Ag}$ buffer layers.

peak, indicating that the films are highly textured. The intensity of the Au peak is 10 times that of the Ag peak, whereas the ratio of the electron densities squared is only 2.8 . This result suggests that the Au buffer layers exhibit either a higher degree of crystallinity or a higher degree of texture, either of which could lead to the differences in anisotropy. The presence of a weak [200] diffraction peak for the $\mathrm{Ag}$ buffer layer, but not for the Au buffer layer (see Fig. 2), is direct evidence that the Au buffer layer is more completely textured than the $\mathrm{Ag}$ buffer layer.

To further test these ideas, we carried out annealing experiments, where the buffer layer was annealed prior to deposition of the $\mathrm{Co} / \mathrm{Ni}$ multilayer. Annealing the Ag buffer layer in vacuum at $400{ }^{\circ} \mathrm{C}$ for $1.5 \mathrm{~h}$ prior to depositing the $\mathrm{Co} / \mathrm{Ni}$ multilayer resulting in significant changes in the shape of the perpendicular hysteresis loop. The remanence ratio $M_{r} / M_{s}$ of the $\mathrm{Co} / \mathrm{Ni}$ multilayers increased considerably, and the coercivity increased by a factor of nearly 5 . However, the easy magnetization direction remained in the film plane. Similar annealing experiments on Au buffer layer resulted in only minor changes in the hysteresis loops. One can specu-
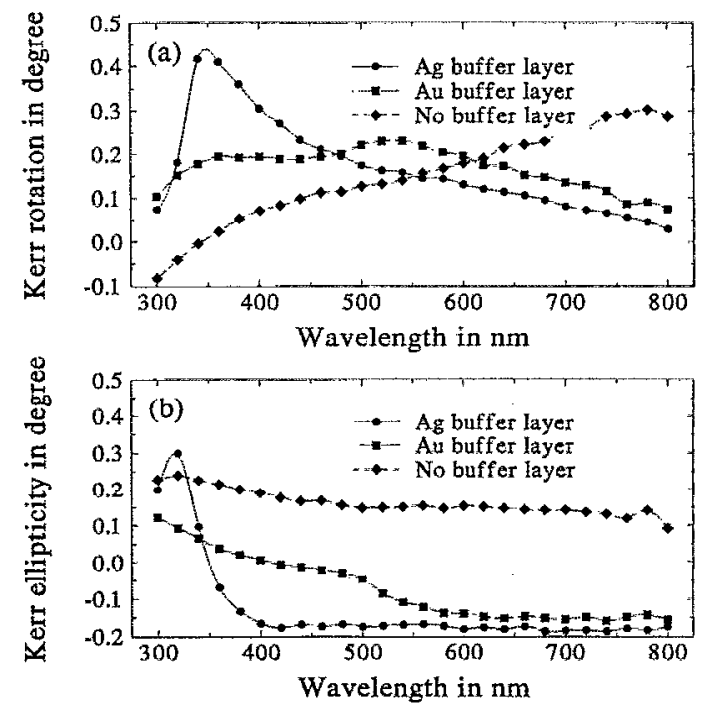

FIG. 3. Wavelength dependencies of $\mathrm{Co}(0.2) / \mathrm{Ni}(0.8) \times 16$ multilayers (a) polar Kerr rotation, (b) polar Kerr ellipticity.

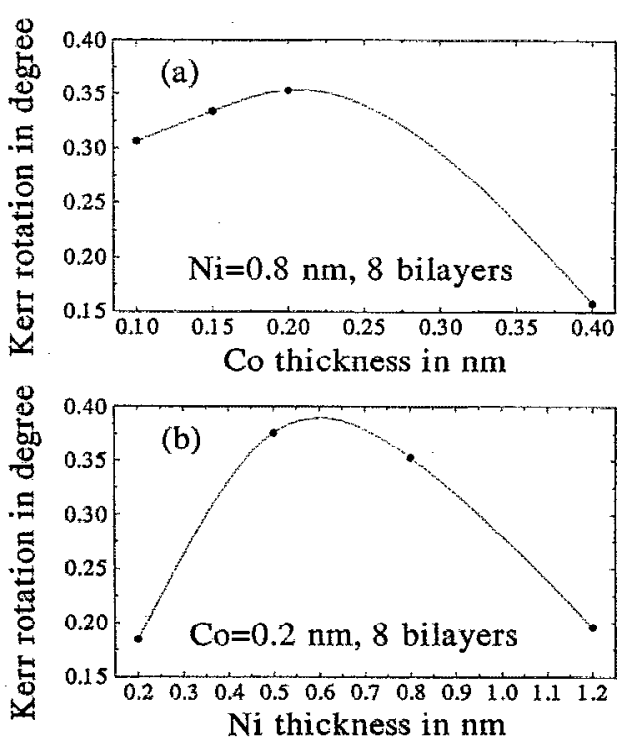

FIG. 4. Polar Kerr rotation at $350 \mathrm{~nm}$ as a function of (a) Co thickness and (b) $\mathrm{Ni}$ thickness for multilayers on $\mathrm{Ag}$ buffer layers.

late that if the [111] texture of the Ag buffer layer could be improved, $\mathrm{Co} / \mathrm{Ni}$ multilayers deposited on $\mathrm{Ag}$ might also show PMA.

The wavelength dependencies of $\theta_{k}$ and $\epsilon_{k}$ for $\mathrm{Co} / \mathrm{Ni}$ multilayers on both $\mathrm{Au}$ and $\mathrm{Ag}$ buffer layers are shown in
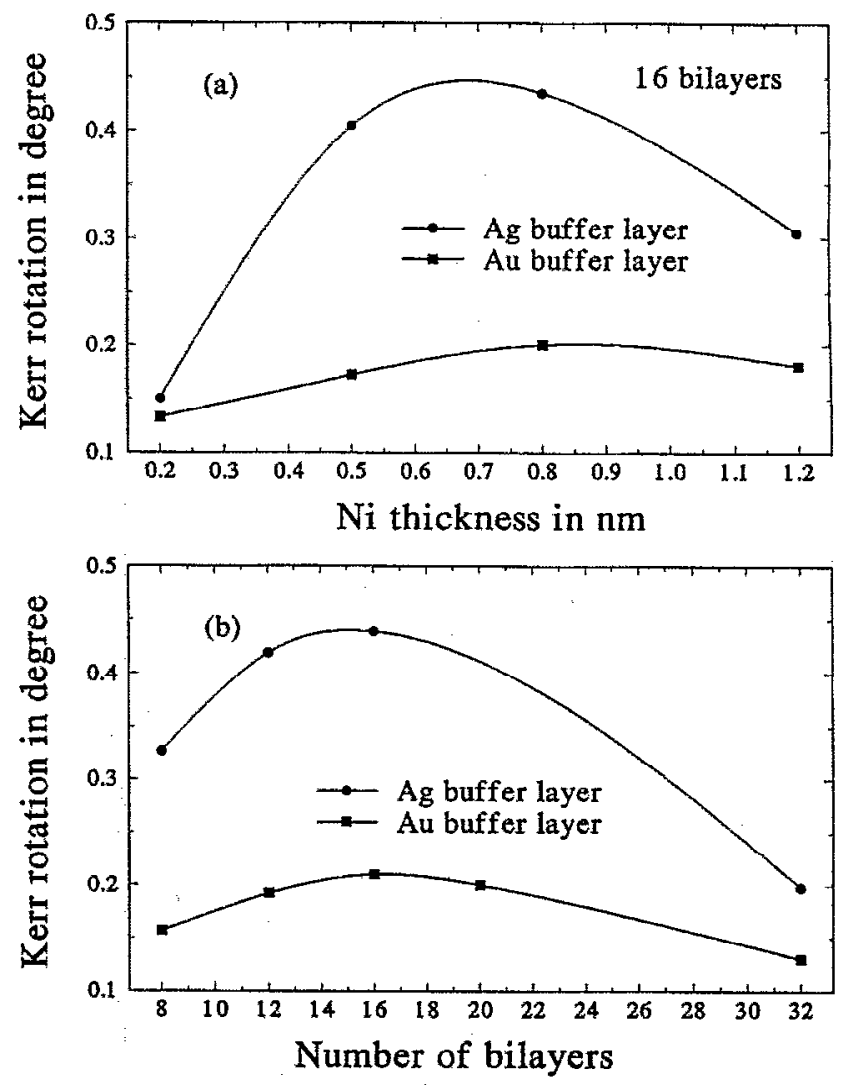

FIG. 5. Polar Kerr rotation at $350 \mathrm{~nm}$ as a function of (a) Ni thickness at $\mathrm{Co}=0.2 \mathrm{~nm}$, (b) bilayer numbers for $\mathrm{Co}(0.2) / \mathrm{Ni}(0.8)$ multilayers on $\mathrm{Ag}$ and Au buffer layers. 
Fig. 3. For Co/Ni multilayer thickness near $10 \mathrm{~nm}$, the optical effects of the buffer layer or the glass substrate is considerable, ${ }^{9}$ since the magnitudes of $\theta_{k}$ and $\epsilon_{k}$ are due to a combination of the magneto-optical properties of the $\mathrm{Co} / \mathrm{Ni}$ multilayer and the optical properties of the buffer layer. From Fig. 3, we note that the peak of $\theta_{k}$ for $\mathrm{Co} / \mathrm{Ni}$ on $\mathrm{Ag}$ falls at $350 \mathrm{~nm}$, or at about the same wavelength where $\epsilon_{k}$ drops rapidly. These two effects occur where the optical properties of $\mathrm{Ag}$ are changing rapidly due to $d$-band transitions. ${ }^{11}$ Similar, but less dramatic, effects are noted for $\mathrm{Co} / \mathrm{Ni}$ on $\mathrm{Au}$. It should also be noted that the short-wavelength polar Kerr rotations of $\mathrm{Co} / \mathrm{Ni}$ multilayers with $\mathrm{Au}$ buffer layers are considerably larger than those of rare-earth-transition-metal alloys. 11

We varied the individual $\mathrm{Co}$ and $\mathrm{Ni}$ layer thicknesses, and also the number of bilayers, to optimize the polar Kerr rotation, and the results are shown in Figs. 4 and 5. The maximum polar Kerr rotation is obtained for $C 0 \approx 0.2 \mathrm{~nm}$, $\mathrm{Ni} \approx 0.6 \mathrm{~nm}$, at about 16 bilayers. The Kerr rotation for $\mathrm{Co} / \mathrm{Ni}$ on $\mathrm{Ag}$ is considerably larger than that of $\mathrm{Co} / \mathrm{Ni}$ on $\mathrm{Au}$ (see Fig. 5), primarily because the measurements were performed at $\lambda=350 \mathrm{~nm}$, where the optical properties of $\mathrm{Ag}$ cause a considerable enhancement of the Kerr rotation.

\section{SUMMARY AND CONCLUSIONS}

Sputtered $\mathrm{Co} / \mathrm{Ni}$ multilayers show perpendicular magnetic anisotropy when deposited on a Au buffer layer, but in-plane anisotropy when deposited on a $\mathrm{Ag}$ buffer layer. This difference most likely arises because the Au buffer layers are more completely oriented with the [111] direction perpendicular to the film plane. The optical properties of the buffer layer also strongly affect the magnitude of the Kerr rotation. The largest Kerr rotation measured was $0.44^{\circ}$ for $\mathrm{Co}(0.2 \mathrm{~nm}) / \mathrm{Ni}(0.6 \mathrm{~nm}) \times 16$ bilayers on a $\mathrm{Ag}$ buffer layer.

\section{ACKNOWLEDGMENTS}

The authors would like to thank Z. S. Shan, D. X. Wang, and $S$. Nafis for assistance and helpful discussion. We are grateful to the National Science Foundation for financial support under Grant No. DMR-9222976.

${ }^{1}$ See, for example, Science and Technology of Nanostructured Magnetic Materials, cdited by G. C. Hadjipanayis and G. A. Prinz (Plenum, New York, 1991).

${ }^{2}$ F. J. A. den Broeder, W. Hoving, and P. J. H. Bloemen, J. Magn. Magn. Mater. 93, 562 (1991).

${ }^{3}$ P. F. Carcia, A. D. Meinhaldt, and A. Suna, Appl Phys. Lett. 47, 178 (1985).

${ }^{4}$ B. N. Engel, C. D. England, R. A. Vanleeuwen, M. H. Wiedmann, and C. M. Falco, Phys. Rev. Lett. 67, 1910 (1991).

${ }^{5}$ G. H. O. Daalderop, P. J. Kelly, and F. J. A. den Broeder, Phys. Rev. Lett. 68, 682 (1992).

${ }^{6}$ F. J. A. den Broeder, H. W. van Kesteren, W. Hoving, and W. B. Zeper, Appl. Phys. Lett. 61, 1468 (1992).

${ }^{7}$ L. Y. Chen and J. A. Woollam, in Proceedings of the SPIE 33rd Annual International Symposium on Optical and Opto-electronic Applied Science and Engineering, 1166, 267 (1989).

${ }^{8}$ F. J. A. den Broeder, E. Janssen, W. Hoving, and W. B. Zeper, IEEE Trans. Magn. 28, 2760 (1992).

${ }^{9}$ P. He, William A. McGahan, and J. A. Woollam, J. Appl. Phys. 69, 4021 (1991)

${ }^{10}$ Frederick Wooten, Optical Properties of Solids (Academic, New York, 1972).

${ }^{11}$ P. F. Carcia, W. B. Zeper, H. W. yan Kesteren, B. A. J. Javobs, and J. H. M. Spurit, in Proceedings of the Magneto-Optical Recording International Symposium, 151 (1991). 